\title{
Assessment of Cervical Vertebral Bone Mineral Density in Adolescents Undergoing Functional Appliance Treatment
}

\author{
Scherene Basheer ${ }^{1}$, Suma Thimmaiah ${ }^{2}$, Rajkumar S Alle ${ }^{3}$
}

\begin{abstract}
Aim: The cervical vertebral maturation (CVM) method has proved to be effective to assess the adolescent growth peak in both body height and mandibular size. The aim of this study was to evaluate whether cone-beam computed tomography (CBCT) images can be used to detect the changes of cervical vertebral bone mineral density (BMD) distribution and whether these changes are associated with CVM changes and mandibular length.

Materials and methods: Samples were collected from the patients of age group between 9 years and 15 years of both sexes, who reported to the Department of Orthodontics and Dentofacial Orthopedics, RajaRajeswari Dental College and Hospital, Bengaluru. All the measurements were done on constructed CBCT three-dimensional images. Gray levels, which are equivalent to the BMD, were obtained for C2 and C3 vertebrae at pretreatment (T1) and six months after starting the treatment (T2). The vertebral variables [mean, standard deviation (SD)], CVM stages, and mandibular length between $\mathrm{T} 1$ and $\mathrm{T} 2$ were compared.

Results: Significant changes in the examined variables were detected during the observation period. The BMD values showed a positive correlation with mandibular length increments.

Conclusion: The $\mathrm{CBCT}$ is an effective tool to analyze the volumetric parameter of $\mathrm{BMD}$ in routine dentofacial orthopedics and the BMD distribution changed because of active bone remodeling during the maturation.

Clinical significance: This study proves that CBCT imaging can provide additional information about the growth status of a patient above and beyond that obtained from two-dimensional cephalometric radiographs. $\mathrm{CBCT}$ is an effective tool to analyze the volumetric parameter of BMD in routine dentofacial orthopedics with better accuracy and minimum distortion.

Keywords: Bone mineral density, Cervical vertebral maturation, Cone-beam computed tomography, Retrospective study.

The Journal of Contemporary Dental Practice (2020): 10.5005/jp-journals-10024-2880
\end{abstract}

\section{INTRODUCTION}

The assessment of skeletal maturity status and knowledge about the amount of skeletal growth remaining is necessary during the treatment planning for growth-modification appliances. ${ }^{1}$ The evaluation of skeletal age is essential to determine the best treatment timing of functional appliances and orthognathic surgery. ${ }^{2}$ Various methods have been proposed for the assessment of skeletal maturity which includes peak height velocity, skeletal maturation of hand wrist, dental age, voice change in males, menarche, and cervical vertebral maturation (CVM). Among these, the CVM method has proved to be the most effective.

Growth modification therapy using functional appliances gives maximum response during the circumpubertal growth period. The rational treatment planning in class II skeletal discrepancies with mandibular deficiencies demands a reliable biologic indicator that can detect the pubertal spurt in mandibular growth. ${ }^{3}$

The shortcoming of the CVM method is that the different stages are determined based on the changes in the shape and size of cervical vertebrae on a cephalogram which is a two-dimensional diagnostic tool. Thus, the CVM method provides qualitative data based on the subjective assessment increasing the possibility of observer bias. Many clinical studies observed poor reliability and repeatability of the CVM method for skeletal maturity assessment. Accurate quantitative analytical methods that allow numeric comparisons between groups are more useful than qualitative methods that rely on individual interpretations. ${ }^{4}$ The cone-beam computed tomography (CBCT) gives information about bone
${ }^{1-3}$ Department of Orthodontics and Dentofacial Orthopedics, RajaRajeswari Dental College and Hospital, Bengaluru, Karnataka, India

Corresponding Author: Scherene Basheer, Department of Orthodontics and Dentofacial Orthopedics, RajaRajeswari Dental College and Hospital, Bengaluru, Karnataka, India, Phone: +91 9901717835, e-mail: scherenebasheer@gmail.com

How to cite this article: Basheer S, Thimmaiah S, Alle RS. Assessment of Cervical Vertebral Bone Mineral Density in Adolescents Undergoing Functional Appliance Treatment. J Contemp Dent Pract 2020;21(7):756-759.

Source of support: Nil

Conflict of interest: None

mineral density (BMD) which is based on the gray scales of the images obtained. ${ }^{5}$ The gray level is the range of shades of gray in the pixels. The shades of gray are caused due to the X-ray attenuation coefficient due to variations in tissue density. It was observed that the changes in the gray level and thereby the BMD changes correspond to the changes in various physiological events of bone development during the growth. ${ }^{1}$

So, in the present study, CBCT scan is used to assess the changes in cervical vertebral BMD in adolescents undergoing functional appliance therapy and to compare these changes with CVM stages and changes in mandibular length.

(-) The Author(s). 2020 Open Access This article is distributed under the terms of the Creative Commons Attribution 4.0International License (https://creativecommons. org/licenses/by-nc/4.0/), which permits unrestricted use, distribution, and non-commercial reproduction in any medium, provided you give appropriate credit to the original author(s) and the source, provide a link to the Creative Commons license, and indicate if changes were made. The Creative Commons Public Domain Dedication waiver (http://creativecommons.org/publicdomain/zero/1.0/) applies to the data made available in this article, unless otherwise stated. 

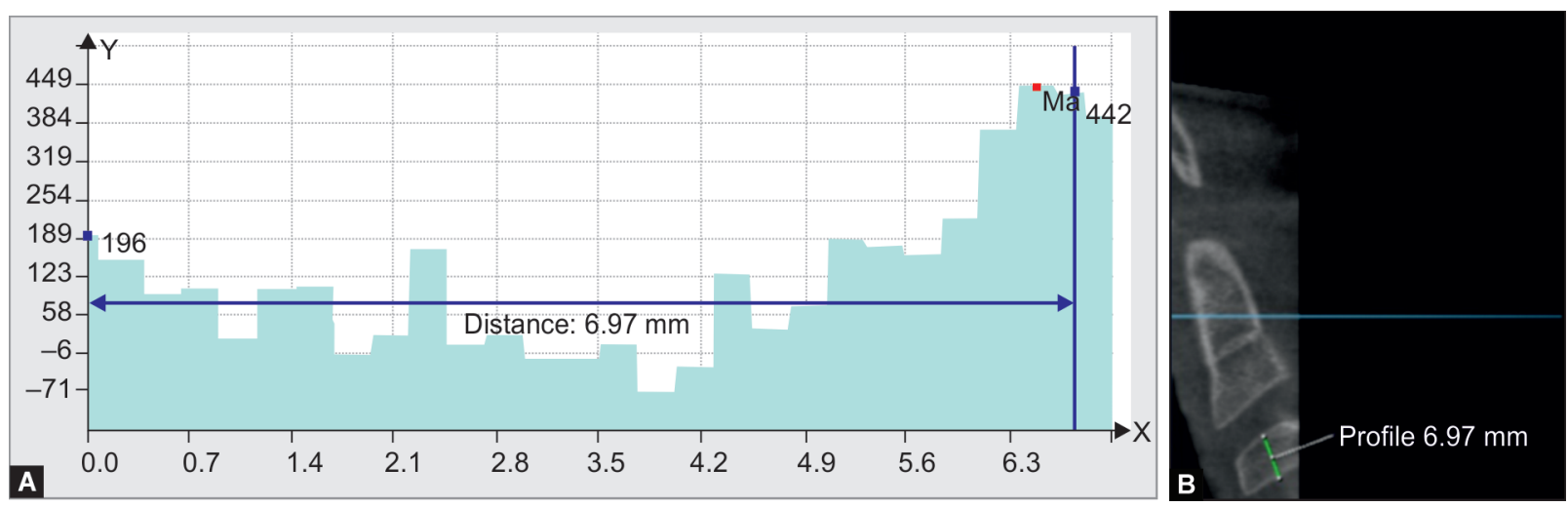

Figs $1 \mathrm{~A}$ and B: Profile of gray-level values of $\mathrm{C} 3$ from $\mathrm{CBCT}$

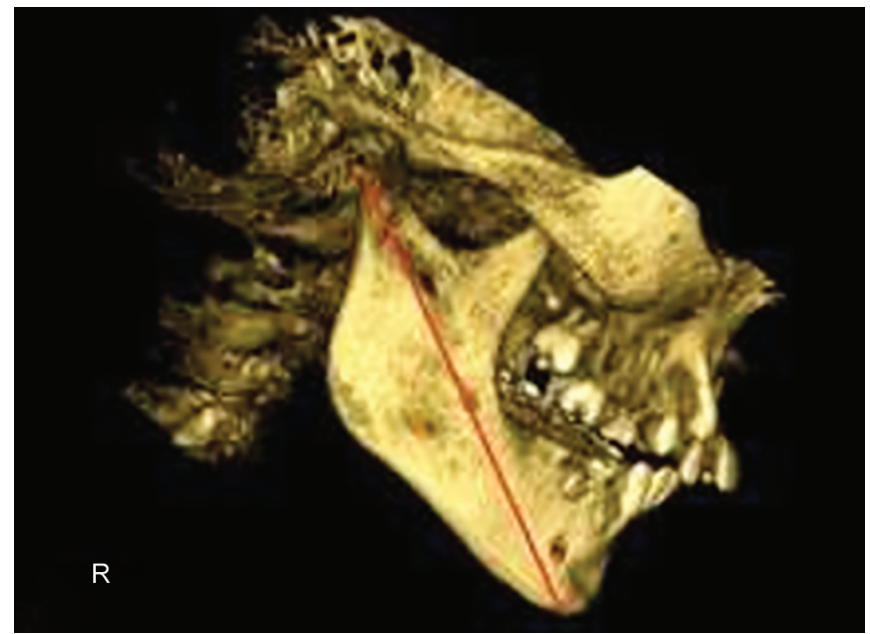

Fig. 2: Length of mandible distance from condylion to gnathion

\section{Materials and Methods}

The adolescent patients of age group 9-15 years, of both sexes who received functional appliance therapy in the Department of Orthodontics and Dentofacial Orthopedics, RajaRajeswari Dental College and Hospital, Bengaluru, were selected for the study. The patients with craniofacial anomalies, facial asymmetries, orthognathic surgery, rapid maxillary expansion, and extractions were excluded from the study. Twenty three-dimentional CBCT images from 10 subjects were obtained at pretreatment $(\mathrm{TI})$ and six months from the start of the treatment (T2). One pretreatment hand wrist radiograph was obtained from each patient to assess the growth status. The subjects were explained about the type of the study and consent was obtained from them regarding the same.

The CBCT images were taken at $12 \mathrm{~mA}$ and $70-90 \mathrm{kV}$ with a Scanora Soredex scanner with the patient seated in the natural head position. Each whole image was first cropped to isolate a smaller field of view surrounding the vertebra of interest, either C2 or C3. Gray levels, which are equivalents of the BMD, were obtained for $\mathrm{C} 2$ and $\mathrm{C} 3$ at $\mathrm{T} 1$ and $\mathrm{T} 2$ at the same anatomical positions in the vertebral body (Fig. 1). This process was repeated for both C2 and C3 for all 20 images.

The CVM stage was categorized according to the Hassel and Farman method. ${ }^{6}$ This method categorizes CVM into six stages depending upon the change in shape and concavities of the cervical vertebrae C2, C3, and C4. The mandibular length was measured as the distance from condylion (most posterior-superior point on the condyle), to anatomic gnathion (midpoint between the most anterior-inferior points on the bony chin) (Fig. 2). The vertebral variable (mean, SD), CVM stages, and mandibular length between $\mathrm{T} 1$ and $\mathrm{T} 2$ were compared.

\section{Statistical Analysis}

The study data were analyzed using the SPSS software (Statistical Package for Social Sciences for Windows, version 22.0. Released 2013. Armonk, NY: IBM Corp). Wilcoxon signed-rank test was used to compare the mean BMD values in C2 and C3 areas between preand post-functional therapy treatment time intervals. Student's paired $t$ test was used to compare the mean mandibular length (in $\mathrm{mm}$ ) between pre- and post-functional therapy treatment time intervals on the right and left sides. Mann-Whitney $U$ test was used to compare the mean BMD values in C2 and C3 areas and mandibular length based on CVM stages during the pre- and posttreatment time intervals. Spearman's correlation test was used to estimate the relationship between the BMD values on C2 and C3 areas with right and left mandibular length during the pre- and posttreatment intervals. The level of significance ( $p$ value) was set at $p<0.05$ for all tests.

\section{Results}

The mean of the mean gray levels of both C2 and C3 showed significant increase in post-functional treatment (T2) (see Table 1). The mean of the mean gray levels for $C 2$ vertebral body was significantly lower than that for $\mathrm{C} 3$ vertebral body both before (T1) and after (T2) treatment. The mean BMD values of C3 showed more increase post-functional therapy than the mean BMD values of C2 post-functional therapy.

The SD of gray levels was significantly greater before treatment than after treatment for C2 and C3 (Table 1). The SD values were more for C3 in pretreatment, but SD values decreased to the same levels in both $\mathrm{C} 2$ and $\mathrm{C} 3$ during the posttreatment.

The mandibular length on the both sides showed an increase during the observation time interval. The mandibular length on the right side showed a mean difference of -0.93 between pre- and post-functional therapy time intervals and the left side showed a mean difference of -1.73 (Table 2 ).

A positive correlation between BMD values and mandibular lengths is shown in the pre- and posttreatment intervals (Table 3).

The level of significance ( $p$ value) was set at $p<0.05$ for all tests. 
Cervical Vertebral Bone Mineral Density in Adolescents

Table 1: Comparison of mean BMD values in C2 and C3 areas between the pre- and post-functional therapy treatment time intervals

\begin{tabular}{llllllll}
\hline Areas & Time & $N$ & Mean & SD & Mean diff. & $Z$ & Z value \\
\hline C2 & Pre-Rx & 9 & 338.94 & 60.12 & -52.67 & -2.666 & 0.008 \\
& Post-Rx & 9 & 391.61 & 52.97 & & -2.666 & 0.008 \\
C3 & Pre-Rx & 9 & 344.11 & 85.20 & -55.72 & & \\
& Post-Rx & 9 & 399.83 & 53.88 & & & \\
\hline
\end{tabular}

Table 2: Comparison of mean mandibular length (in $\mathrm{mm}$ ) between the pre- and post-functional therapy treatment time intervals on the right and left sides

\begin{tabular}{llllllll}
\hline Side & Time & $N$ & Mean & SD & Mean diff. & $T$ & T value \\
\hline Right & Pre-Rx & 9 & 93.29 & 5.48 & -0.93 & -5.621 & $<0.001$ \\
& Post-Rx & 9 & 94.22 & 5.32 & & -5.718 & $<0.001$ \\
Left & Pre-Rx & 9 & 93.71 & 5.76 & -1.73 & & \\
& Post-Rx & 9 & 95.44 & 6.18 & & & \\
\hline
\end{tabular}

Table 3: Spearman's correlation between the BMD values on $\mathrm{C} 2$ and $\mathrm{C} 3$ areas with right and left side lengths during the pre- and post-Rx intervals

\begin{tabular}{lllll}
\hline Time & Areas & Values & Right side & Left side \\
\hline Pre-Rx & C2 & Rho & 0.37 & 0.37 \\
& & $p$ value & 0.33 & 0.33 \\
& & $N$ & 9 & 9 \\
& C3 & Rho & 0.28 & 0.28 \\
& & $p$ value & 0.46 & 0.46 \\
Post-Rx & C2 & N & 9 & 9 \\
& & Rho & 0.30 & 0.30 \\
& & $p$ value & 0.43 & 0.43 \\
& & $N$ & 9 & 9 \\
& C3 & Rho & 0.22 & 0.22 \\
& & $p$ value & 0.58 & 0.58 \\
& & $N$ & 9 & 9
\end{tabular}

The correlation coefficients are denoted by "rho"

\section{Discussion}

Lamparski in 1975 introduced the methods of maturational status assessment using cervical vertebrae. It was implemented by O'Reilly and Yanneilo and Bacetti et al. ${ }^{7,8}$ However, Gabriel et al. emphasized on using more sensitive parameters instead of using morphological parameters in assessing CVM, thus to avoid intra and interobserver bias., ${ }^{9,10}$

Nestman et al. in the year 2011 reported that a classification of vertebral bodies based on the shapes (changes in concavity) had poor reproducibility. This made the CVM method to fail as an accurate growth assessment tool. ${ }^{11}$ Previous methods using standard lateral cephalograms observe the shape changes of cervical vertebrae in various growing periods, whereas the measurement of BMD using $\mathrm{CBCT}$ provides a third dimension putting forth a quantitative analysis. ${ }^{12}$

Quantitative bone age assessment methods were evaluated by Chatzigianni and Halazonetis. Three-dimensional imaging opened new vistas in diagnosis and treatment planning. This led to the investigation by Shim et al. in 2012 to assess skeletal maturation using CBCT. They measured surfaces, areas, and volumes to assess skeletal age. ${ }^{13}$
Naitoh et al. in 2009 suggested that voxel values of mandibular trabecular bone derived from CBCT could be used to estimate the bone density.

In 2004, Crawford et al. digitally isolated cervical vertebrae from $\mathrm{CBCT}$ images and studied their volume and gray-level histograms and concluded that BMD and volume of cervical vertebrae were changed during the maturation. ${ }^{1}$

This study was aimed to determine whether additional information in the form of BMD distribution would be available using CBCT and whether it is useful in assessing skeletal maturity and growth potential. It was found that the BMD does change predictably during the adolescent growth period. The means of gray-level profiles of C2 and C3 vertebrae, which correspond to average BMD (BMD), were assessed from the CBCT images. The posttreatment timepoint showed greater mean gray level than at the pretreatment timepoint. As higher gray values indicate a higher level of mineralization, this indicates that there is a greater difference in mineralization between the two vertebrae after treatment than before treatment. This implies that active mineralization took place during the observation period, that is, adolescent growth period. The above results indicate that the CBCT-based analysis of gray levels of cervical vertebrae could provide information of BMD distribution that is changing along with skeletal maturation and mandibular growth.

The SD of gray levels indicates the variability of BMD resulting from bone modeling and remodeling. As the newly forming bone tissue has less tissue mineral density than preexisting bone tissue, the variability of tissue mineral density increases. In the current study, the SD of gray levels significantly decreased in both C2 and C3 posttreatments indicating that active bone remodeling has taken place during the observation period with more amount of less mineralized newly formed bone present at the posttreatment period.

The new bone formation occurs in two ways. Uncoupled bone modeling where resorption of preexisting bone tissue and formation of new bone tissue occur independently or by coupled bone remodeling process which comprises new bone formation after resorption. The newly formed bone tissue has less tissue mineral density than preexisting bone tissue. This causes variability of tissue mineral density. ${ }^{14}$

The constancy of CBCT-based BMD measurements is questionable due to the variations in the thickness of soft tissues 
and the head position during the scan..$^{15}$ To alleviate these factors, we compared the gray-level parameters of consecutive vertebrae ( $C 2$ and $C 3$ ) in the same $\mathrm{CBCT}$ image.

The use of CBCT in skeletal age assessment should be weighed on cost-benefit analysis practice of "as low as reasonably achievable" principle is mandatory. Effective dose from a typical orthodontic CBCT large field of view scan using a Scanora scanner is $68 \mathrm{mSv}$, while the dose from a digital lateral cephalometric radiograph is $5.6 \mathrm{mSv}$. However, in conditions like impacted or ectopic tooth, pathologies, temporomandibular dysfunctions, airway compromises, and cleft palate where routine lateral cephalogram is not sufficient enough to provide pertinent diagnostic data and $\mathrm{CBCT}$ imaging becomes obligatory, the clinicians can assess skeletal age from readily available $\mathrm{CBCT}$, thus avoiding additional radiographic exposure. ${ }^{16}$

The CBCT has significant advantages like low effective radiation dose, low operational cost and high resolution level which can be used for obtaining three-dimensional images of craniofacial structures, the CBCT machine is compact and is best suited for dental clinics and it has been proposed as a diagnostic method for the determination of BMD.

\section{Conclusion}

Cervical vertebrae exhibit increase in BMD values during the peak mandibular growth period which is the optimal time for functional appliance therapy, and the BMD values showed a positive correlation with mandibular length increments and CVM stages.

\section{Clinical Significance}

This study proves that $C B C T$ imaging may provide additional information about the growth status of a patient above and beyond that obtained from two-dimensional cephalometric radiographs. $\mathrm{CBCT}$ is an effective tool to analyze the volumetric parameter of BMD in routine dentofacial orthopedics with better accuracy and minimum distortion.

\section{References}

1. Crawford B, Kim DG, Moon ES, et al. Cervical vertebral bone mineral density changes in adolescents during orthodontic treatment. Am J Orthod Dentofacial Orthop 2014;146(2):183-189. DOI: 10.1016/j. ajodo.2014.04.019.

2. Baccetti T, Franchi L, McNamara Jr JA. An improved version of the cervical vertebral maturation (CVM) method for the assessment of mandibular growth. Angle Orthod 2002;72(4):316-323.
3. Chen F, Terada K, Hanada K. A new method of predicting mandibular length increment on the basis of cervical vertebrae. Angle Orthod 2004;74(5):630-634.

4. da Silva Campos MJ, de Souza TS, Júnior SL, et al. Bone mineral density in cone beam computed tomography: only a few shades of gray. World J Radiol 2014;6(8):607. DOI: 10.4329/wjr.v6.i8.607.

5. Naitoh M, Hirukawa A, Katsumata A, et al. Evaluation of voxel values in mandibular cancellous bone: relationship between cone-beam computed tomography and multislice helical computed tomography. Clin Oral Implants Res 2009;20(5):503-506. DOI: 10.1111/j.16000501.2008.01672.x.

6. Hassel B, Farman AG. Skeletal maturation evaluation using cervical vertebrae. Am J Orthod Dentofacial Orthop 1995;107(1):58-66. DOI: 10.1016/S0889-5406(95)70157-5.

7. Franchi L, Baccetti T, McNamara Jr JA. Mandibular growth as related to cervical vertebral maturation and body height. Am J Orthod Dentofacial Orthop 2000;118(3):335-340. DOI: 10.1067/ mod.2000.107009.

8. O'Reilly MT, Yanniello GJ. Mandibular growth changes and maturation of cervical vertebrae: a longitudinal cephalometric study. Angle Orthod 1988;58(2):179-184.

9. Cassetta M, Stefanelli LV, Pacifici A, et al. How accurate is CBCT in measuring bone density? A comparative CBCT-CT in vitro study. Clin Implant Dent Relat Res 2014;16(4):471-478. DOI: 10.1111/cid.12027.

10. Gabriel DB, Southard KA, Qian F, et al. Cervical vertebrae maturation method: poor reproducibility. Am J Orthod Dentofacial Orthop 2009;136(4):478.e1-478.e7. ; discussion 478-80, 10.1016/ j.ajodo.2007.08.028.

11. Nestman TS, Marshall SD, Qian F, et al. Cervical vertebrae maturation method morphologic criteria: poor reproducibility. Am J Orthod Dentofacial Orthop 2011;140(2):182-188. DOI: 10.1016/ j.ajodo.2011.04.013.

12. Santiago RC, de Miranda Costa LF, Vitral RW, et al. Cervical vertebral maturation as a biologic indicator of skeletal maturity: a systematic review. Angle Orthod 2012;82(6):1123-1131. DOI: 10.2319/103111673.1.

13. Shim JJ, Heo G, Lagravère MO. Assessment of skeletal maturation based on cervical vertebrae in CBCT. Int Orthod 2012;10(4):351-362. DOI: 10.1016/j.ortho.2012.09.005.

14. Katsumata A, Hirukawa A, Okumura $S$, et al. Relationship between density variability and imaging volume size in cone-beam computerized tomographic scanning of the maxillofacial region: an in vitro study. Oral Surg Oral Med Oral Pathol Oral Radiol Endod 2009;107(3):420-425. DOI: 10.1016/j.tripleo.2008.05.049.

15. Guerra EN, Almeida FT, Bezerra FV, et al. Capability of CBCT to identify patients with low bone mineral density: a systematic review. Dentomaxillofac Radioly 2017;46(8):20160475. DOI: 10.1259/ dmfr.20160475.

16. Shi H, Scarfe WC, Farman AG. Three-dimensional reconstruction of individual cervical vertebrae from cone-beam computed-tomography images. Am J Orthod Dentofacial Orthop 2007;131(3):426-432. DOI: 10.1016/j.ajodo.2005.12.031. 